\title{
Career prospects of part time senior registrar anaesthetists
}

\author{
JENNIFER M EATON
}

In June 1979 a questionnaire was sent to the 35 part time senior registrar anaesthetists enrolled with, but not yet accredited by, the Joint Committee for Higher Training of Anaesthetists. They were asked for details of their previous experience, present job, and future aspirations. The survey elicited a high response rate and the findings have been published. 'It was decided to follow up the 31 respondents by means of a yearly questionnaire to assess their progress. A further two members of the group who were traced after publication were included in the follow up survey.

Information was sought concerning progress of training, future aspirations, and difficulties encountered in finding a consultant post. Comments and advice for other doctors with domestic commitments were also invited. Six years of the survey have now been completed.

\section{Results}

Of the 33 senior registrars in the follow up group, only three were lost to the survey; two are believed to be practising anaesthesia in Australia and the third is probably no longer in training. One respondent did not take up her senior registrar post and has not returned to anaesthesia during the period. The remaining 29 respondents are committed to a career in anaesthesia in Great Britain. Sixteen are married to doctors and 14 of the latter are now hospital consultants. During the course of the survey 11 of the group had babies, two were divorced, and one was widowed. Due to family commitments one senior registrar suspended her training for two and a half years and joined the retainer scheme. Another respondent who had moved just before the original survey spent two years as a clinical assistant while waiting for her part time senior registrar post to be re-established.

\section{TRAINING}

Overall, part time higher professional training was thought to be satisfactory and enjoyable. Those senior registrars based in nonteaching hospitals were generally seconded to larger centres for specialist experience. This often meant considerable travelling. Specific deficiencies, cited by eight respondents, included lack of research time, insufficient consultant contact, and lack of specialist, administrative, and teaching experience. As in the 1979 survey the respondents thought that there was insufficient recognition of the amount of extra work contributed by part timers. Two respondents were, however, granted extra sessions to cover preoperative and postoperative work, etc, and thus reduced the length of time in post required for accreditation. Two other respondents were also able,

Department of Anaesthetics, Frenchay Hospital, Bristol BS16 ILE

JENNIFER M EATON, MB, FFARCS, consultant anaesthetist after negotiation with the Joint Committee for Higher Training of Anaesthetists, to reduce the period of higher training.

A lack of research opportunities was also a feature of the original survey. During the past six years 16 of the respondents have had work published and two have been awarded prizes.

Three senior registrars worked full time abroad for one month, one year, and two years respectively during their training. Apart from these periods, none of the respondents moved from one region to another during the course of the follow up.

The security of tenure of part time senior registrar posts varied: in one case a contract was terminated one year after accreditation; in other cases contracts were extended for a further three to four years.

\section{FUTURE ASPIRATIONS}

Initially, only two senior registrars aspired to a full time consultant career; the remainder hoped to work seven sessions or less. During the course of the follow up this position changed until 15 wished to work full time.

\section{CONSULTANT POSTS}

Of the 29 respondents pursuing a career in anaesthesia in this country, 18 are now consultants. Of these, five have contracts of seven sessions or less and 13 are full time or maximum part time. Of the consultants initially appointed for five or six sessions, three have since increased their commitment by one or two sessions. A further four respondents are in long term locum consultant posts, four have completed their higher training but are still employed as senior registrars, and three are not yet accredited. Of those respondents without substantive consultant posts, only two have been accredited for more than two and a half years.

At the time of their appointment 10 of the consultants were aged between 30 and 39 , seven were between 40 and 49 , and one was over 50 .

Fifteen of the respondents obtained their consultant posts within one year of accreditation and the remaining three within two years. Of the latter three, one spent a year after accreditation as a clinical assistant.

Only three of the consultants moved to a different area on appointment; two of these moved with their husbands, who obtained consultant posts at the same time. A further three moved locally in order to live within a 10 mile radius of their new hospital. One respondent, while maintaining her main home, has had to buy a pied à terre closer to her hospital, and another lives in when on call in order to avoid moving.

Eleven consultants were appointed at their first application, six made two or three applications, and one made over 20. Two respondents applied jointly with other part timers but were unsuccessful. Of the eight respondents with their accreditation who have not yet obtained a consultant post, seven had made at least one application. Three respondents offered seven sessions for a consultant post advertised as full time or maximum part time, but only one was successful. 


\section{ADVICE TO DOCTORS WITH DOMESTIC COMMITMENTS}

Almost all the respondents emphasised the advantages of obtaining the fellowship of the Faculty of Anaesthetists of the Royal College of Surgeons before opting for part time employment and many recommended working full time as a senior registrar for at least one year. Several thought that job sharing at senior registrar level was a good idea. Prospects for part time employment at consultant level were considered to be poor. Overall, it was thought that part time training was becoming more difficult to set up and the importance of flexibility, attendance at meetings, adequate research, etc, were frequently mentioned.

\section{Discussion}

In general, the quality of part time senior registrar training did not vary over the six years of the follow up survey. Most respondents were satisfied with their training and the specific deficiencies quoted were similar to those found in 1979. There seems to have been some recognition by the departments concerned and the Joint Committee for Higher Training of Anaesthetists of the amount of extra work contributed by part timers; four respondents were able to reduce the period of higher training without increasing the number of "theatre" sessions worked.

There seems to be a lack of research experience among the respondents as judged by published work. It is debatable whether this is due to a lack of opportunity and support or a lack of enthusiasm. In its recommendations for higher training the Joint Committee for Higher Training of Anaesthetists advises participation in clinical investigation and states that publication of work should be encouraged. ${ }^{2}$ In the competition for consultant posts evidence of research work accomplished is obviously an important factor.

Many of the participants in the initial survey had, as expected, moved several times during their training. In the follow up, however, apart from periods abroad, none of the respondents moved from one region to another. This no doubt reflects the fact that women tend to move with their husbands, many of whom were hospital doctors. By the senior registrar stage of training husbands tended to have reached a senior post and thus were relatively static. As the respondent who moved just before the original survey had to wait two years for her part time post to be re-established such geographical stability is probably essential for successful training.

The security of tenure of part time senior registrars was variable and did not seem to be always equivalent to that of their full time colleagues. While no senior registrar contract can be extended indefinitely, most of the respondents with accreditation had made at least one application for a consultant post and surely deserve the customary extensions of contract.

Interestingly, during the course of the survey an increasing proportion of the participants favoured a full time consultant career. This probably reflects a general despondency about the prospects for limited session - that is, five to seven-consultant posts and also the increasing age of children.

The senior registrars in the survey in England and Wales were employed under the terms of the circular PM(79)3. ${ }^{3}$ This states that "any doctor or dentist who obtains a senior registrar post now has a good chance of becoming a consultant at the end of training." The fact that 18 of the 26 accredited respondents in the survey are now consultants would suggest that, in anaesthesia, the scheme has fulfilled its aims. Of those respondents who have completed their higher training but who are without a consultant post, only two have been accredited for more than two and a half years and could, therefore, be said to have encountered real difficulty in finding a consultant job. Only one respondent accepted a subconsultant grade after higher training and this was only as a temporary expedient, while applying for consultant posts.

Most consultants are full time or maximum part time, and among those with true part time contracts (seven sessions or less) there was a tendency to increase their sessions with time. Thus for many of the respondents the need for part time employment was only temporary. There is, however, an important minority, especially among those who had children during their higher training, who wish to continue to work part time. At present the opportunities for five to seven session consultant jobs are limited, but job sharing could provide an alternative. Although neither of the joint applications for whole time consultant posts made during the course of the survey were successful, anaesthesia, with its predominantly sessional commitment, would seem particularly suitable for this type of arrangement.

Despite their prolonged training, all except one of the respondents obtained a consultant post while still in their 30s and 40s and thus have a considerable period of employment ahead of them.

The geographical limitations of part time senior registrars were reflected in the siting of consultant posts; in all but three cases the respondents did not move from their area on appointment. Of the three who did move, only one senior registrar, who was divorced, was relatively free to move anywhere. The two others moved with their husbands. The difficulties entailed in both husband and wife obtaining consultant posts in the same group of hospitals are obviously considerable, but eight couples in the survey achieved it. Of those respondents who have obtained consultant posts, most seemed to do so without too much difficulty in that they were appointed within one year of accreditation and at their first application.

Although the circular $\mathrm{HC}(82) 10$ states that all whole time consultant jobs must be advertised in such a way that doctors with domestic considerations may offer a limited number of sessions, only one respondent successfully exercised this option. ${ }^{4}$ This is not unexpected, as a department requiring another whole time member in order to fulfil its service commitment is unlikely to be able to accept a part timer. The circular makes no recommendations as to how the remaining sessions should be covered.

Although most of the respondents found their training to be satisfactory, their advice to other doctors with domestic commitments was to work full time for as long as possible and preferably until obtaining the fellowship of the Faculty of Anaesthetists. This no doubt reflects the feeling that part time training is becoming more difficult to obtain and in the increasing competition for consultant jobs it may be a disadvantage. Part time training was certainly not considered to be an easy option and many respondents emphasised the importance of research work, etc, so that the part timer's training is truly equivalent to that of her full time colleagues.

\section{Conclusion}

For the respondents in this survey part time senior registrar training must be considered a success as most of those accredited have obtained consultant posts in spite of their geographical limitations. The 1979 circular provided a flexible framework for this training; I do not know whether the new proposals contained in the interim report of the Joint Consultants Committee's working party are an improvement. ${ }^{5}$ Under these new arrangements part time senior registrar posts would be generated by dividing whole time posts. Although this means that part timers would be included in the senior registrar establishment, which is obviously essential for manpower planning, it remains to be seen how easy it will be to "match" trainees with suitable partners while maintaining the flexibility essential to successful part time training.

I should like to thank my colleagues who completed my questionnaires and Mrs L Scott for her secretarial help.

\section{References}

1 Eaton JM. Survey of part time senior registrar anaesthetists. $\mathrm{Br} M e d \mathcal{F}$ 1980;281:758-60. 2 Joint Committee for Higher Training of Anaesthetists. Higher Specialist Training. London: Joint Committee for Higher Training of Anaesthetists, 1979.

3 Department of Health and Social Security. Opportunities for part-time training in the NHS for doctors and dentists with domestic commitments, disability or ill-healhh. London: DHSS, 1979. (PM(79)3.) 4 Department of Health and Social Security. Health services management. The appointment of consultants and senior registrars. London: DHSS, 1982. (HC(82)10.)

5 Anonymous. Part time senior registrar training. Br Med J 1985;290:408.

(Accepted 2.3 fuly 1985) 